\title{
Treating infant colic with the probiotic Lactobacillus reuteri: double blind, placebo controlled randomised trial
}

\author{
(c) (1) (8) OPEN ACCESS
}

\author{
Valerie Sung paediatrician ${ }^{123}$, Harriet Hiscock associate professor $^{123}$, Mimi L K Tang professor ${ }^{123}$, \\ Fiona K Mensah statistician ${ }^{123}$, Monica L Nation honours student ${ }^{23}$, Catherine Satzke research \\ fellow $^{23}$, Ralf G Heine paediatric gastroenterologist/allergist ${ }^{123}$, Amanda Stock paediatrician ${ }^{1}$, \\ Ronald G Barr professor ${ }^{4}$, Melissa Wake professor ${ }^{123}$
}

${ }^{1}$ Royal Children's Hospital, Parkville, Victoria, Australia; ${ }^{2}$ Murdoch Childrens Research Institute Victoria, Australia; ${ }^{3}$ The University of Melbourne, Parkville, Victoria, Australia; ${ }^{4}$ Developmental Neurosciences and Child Health, Child and Family Research Institute, Vancouver, BC, Canada

\begin{abstract}
Objective To determine whether the probiotic Lactobacillus reuteri DSM 17938 reduces crying or fussing in a broad community based sample of breastfed infants and formula fed infants with colic aged less than 3 months.

Design Double blind, placebo controlled randomised trial.

Setting Community based sample (primary and secondary level care centres) in Melbourne, Australia.

Participants 167 breastfed infants or formula fed infants aged less than 3 months meeting Wessel's criteria for crying or fussing: 85 were randomised to receive probiotic and 82 to receive placebo.

Interventions Oral daily $L$ reuteri $\left(1 \times 10^{8}\right.$ colony forming units) versus placebo for one month

Main outcomes measures The primary outcome was daily duration of cry or fuss at 1 month. Secondary outcomes were duration of cry or fuss; number of cry or fuss episodes; sleep duration of infant at 7, 14, and 21 days, and 1 and 6 months; maternal mental health (Edinburgh postnatal depression subscale); family functioning (paediatric quality of life inventory), parent quality adjusted life years (assessment of quality of life) at 1 and 6 months; infant functioning (paediatric quality of life inventory) at 6 months; infant faecal microbiota (microbial diversity, colonisation with Escherichia coll), and calprotectin levels at 1 month In intention to treat analyses the two groups were compared using regression models adjusted for potential confounders.
\end{abstract}

Results Of 167 infants randomised from August 2011 to August 2012, $127(76 \%)$ were retained to primary outcome; of these, a subset was analysed for faecal microbial diversity, $E$ coli colonisation, and calprotectin levels. Adherence was high. Mean daily cry or fuss time fell steadily in both groups. At 1 month, the probiotic group cried or fussed 49 minutes more than the placebo group ( $95 \%$ confidence interval 8 to 90 minutes, $\mathrm{P}=0.02$ ); this mainly reflected more fussing, especially for formula fed infants. The groups were similar on all secondary outcomes. No study related adverse events occurred.

Conclusions $L$ reuteri DSM 17938 did not benefit a community sample of breastfed infants and formula fed infants with colic. These findings differ from previous smaller trials of selected populations and do not support a general recommendation for the use of probiotics to treat colic in infants.

Trial registration Current Controlled Trials ISRCTN95287767.

\section{Introduction}

Infant colic, or excessive crying of unknown cause, affects up to $20 \%$ of infants ${ }^{1}$ and is a major burden to families and health services. Infant colic is often defined by the Wessel's criteria of crying or fussing for three hours or more a day for three days or more per week for three weeks in infants aged less than 3 months. ${ }^{2}$ Although infant colic spontaneously resolves after the first three to four months after birth, it is associated with maternal depression, ${ }^{3}$ early breastfeeding cessation, ${ }^{4}$ and shaken baby syndrome. ${ }^{5}$ Infant distress is one of the most common presenting problems to primary, secondary, and tertiary healthcare sectors, costing the UK healthcare system millions of pounds annually. ${ }^{6}$

The cause of infant colic remains elusive despite decades of research. Psychosocial hypotheses include poor maternal-infant interactions, maternal anxiety and depression, and difficult infant temperament. ${ }^{7}$ Gastrointestinal theories include increased 
intra-abdominal gas, hyperperistalsis, and visceral pain. ${ }^{7}$ One study has suggested that infants with colic may have increased faecal calprotectin levels, ${ }^{8}$ suggesting a possible role for gut inflammation; however, another study suggested no differences in faecal calprotectin levels between infants with and infants without colic. $^{9}$

No single effective treatment for colic exists, and most clinical guidelines recommend support and reassurance as the mainstay of management. ${ }^{10-13}$ The use of hypoallergenic formulas or elimination of cow's milk protein from the diet of mothers who are breast feeding may possibly be effective, ${ }^{10-12}$ yet not all irritable infants respond. ${ }^{14}{ }^{15}$ Anticholinergic drugs (for example, dicycloverine (dicyclomine)) are effective ${ }^{16-18}$ but have potentially dangerous side effects, including breathing difficulties and coma. ${ }^{19}$ An effective, practical, and acceptable intervention for infant colic would represent a major advance in clinical and public health.

Recently, research into the use of probiotics (live micro-organisms that confer a health benefit) for colic has been rapidly gaining momentum. Infants with colic are reported to have increased concentrations of gas forming organisms and proteobacteria such as Escherichia coli in their gut. ${ }^{8-22}$ Colonisation with certain intestinal micro-organisms, such as Bifidobacterium and Lactobacillus species, along with increased intestinal microbial diversity, may protect against infant distress. ${ }^{823}$ Probiotics enhance the mucosal barrier and promote microbial diversity in the gut. ${ }^{24}{ }^{25}$ They may reduce

concentrations of proteobacteria and gas forming coliform and reduce intestinal inflammation. ${ }^{26-30} \mathrm{~A}$ recent meta-analysis of three small, randomised controlled trials of breastfed infants with colic reported that Lactobacillus reuteri noticeably reduced crying time at 21 days post supplementation. ${ }^{31}$ However, one trial was unblinded ${ }^{32}$ two included only infants with mothers on dairy-free diets, ${ }^{32}{ }^{33}$ and none used validated measures of infant distress. No trials have included formula fed infants, which is relevant because colic is associated with early breastfeeding cessation. ${ }^{4}$ Despite these major limitations, the use of probiotics for colic has been rapidly taken up internationally. An urgent need exists for a larger, more rigorous trial that includes infants unselected for feeding method to clarify whether $L$ reuteri is effective for infant colic in the general population.

We determined whether the probiotic $L$ reuteri DSM 17938 benefited infants aged less than 3 months ( $<13$ weeks) with colic, irrespective of feeding mode. We also examined its effect on gut microbiota, faecal calprotectin levels, and $E$ coli colonisation, all implicated in the mechanism of disease. We hypothesised that compared with the placebo (control) group, the $L$ reuteri (treatment) group would show lower mean daily cry or fuss time at 1 month (primary outcome), and at 7,14, and 21 days, and 6 months, and fewer daily episodes of cry or fuss (7, 14, 21 days, 1 and 6 months); longer infant sleep duration (7, 14, 21 days, 1 and 6 months); better mean scores on a standardised measure of maternal mental health; better mean scores on a standardised measure of infant ( 6 months) and family functioning (1 and 6 months); better mean scores on a standardised measure of parent quality adjusted life years (1 and 6 months); and changes in gut microbiota (increased faecal microbial diversity, less $E$ coli colonisation (1 month), and reduced faecal calprotectin levels (1 month)). We hypothesised that these effects would be sustained within the breastfed group and formula fed group of infants.

\section{Methods \\ Trial design}

This was a phase III, double blind, randomised placebo controlled trial. Details of the protocol are described elsewhere. ${ }^{34}$

\section{Participants}

Between August 2011 and August 2012 we recruited participants from a range of services accessed by carers of newborn babies in Melbourne, Australia: the Royal Children's Hospital emergency department, the Royal Children's Hospital Unsettled Babies Clinic (a referral based outpatient clinic), Tweddle Child and Family Health Centre (a mother-infant parenting centre), two maternal child health centres (universal nurse health checks), and paediatricians at the Royal Children's Hospital and in private practices. Families could also contact the study team to be involved.

We recruited healthy term infants less than 13 weeks of age with infant colic, defined by modified Wessel's criteria of crying or fussing for three hours or more a day for three days or more over seven days. The study doctor assessed eligibility through a structured telephone or face to face interview. Fussing was defined as "behaviour that is not quite crying but not awake and content either." ${ }^{35}$ We excluded infants who weighed less than $2500 \mathrm{~g}$ at birth; failed to thrive; had major medical problems; had an allergy to cow's milk protein (confirmed by symptom resolution after a two week trial of hypoallergenic formula or a cow's milk protein-free diet in mothers of breastfed infants); or took solids, antibiotics, or L reuteri at the start of the trial. We also excluded breastfed infants whose mothers took $L$ reuteri at trial start, and caregivers with insufficient English to complete questionnaires.

\section{Intervention}

The treatment was $L$ reuteri DSM $17938\left(0.2 \times 10^{8}\right.$ colony forming units per drop) in an oil suspension, given once daily (five drops orally) for one month. The placebo was maltodextrin in the same oil suspension with the same appearance, colour, and taste as the treatment, identically packaged and stored. Caregivers were instructed to dispense five drops of study liquid onto a spoon to administer to their infants at the same time each day. The dosing of L reuteri is the same as that used in the three previous trials showing effectiveness of the probiotic in managing colic. ${ }^{32-36}$

\section{Randomisation, allocation concealment, blinding}

Randomisation was stratified by method of infant feeding (breast fed $v$ formula fed) and age ( $\leq 6$ weeks $v>6$ weeks, owing to the natural peak in crying at around six weeks of age). We allocated infants who were both breast fed and formula fed to the formula fed stratum. An independent statistician prepared the computer generated randomisation schedule using a block size of two to maintain balance between treatment arms within each stratum. The trial was double blind, whereby treatment allocation was concealed from all study investigators and participants at every phase, including measurement of outcomes. Study investigators allocated infants to one of four randomisation strata according to their age and feeding type. An independent pharmacist (who was not part of the study team and had no access to the study database) then allocated the study identification number to each infant and dispensed the study product according to the randomisation schedule. This randomisation schedule was not revealed to the study investigators until all outcomes analyses 
at one month were complete. The treatment and placebo drops were packaged identically such that study investigators and families were blinded to treatment allocation throughout the study.

\section{Outcomes, adherence, adverse events}

Table $1 \Downarrow$ shows the outcome measures at the different time points. Funding allowed analysis of a subset of faecal samples for microbial diversity, E coli load, and calprotectin levels collected at one month post-intervention. We measured adherence by weekly parental report using a diary, with non-adherence defined as carers reporting discontinuing the intervention within two weeks of trial start. We weighed all bottles before and after intervention to determine equivalence in adherence between the groups. We also assessed for $L$ reuteri in 65 faecal samples. Parents recorded any adverse events weekly. For the six month outcomes, we allowed the last 91 carers in the trial to fill in one day of the study diary instead of two to reduce the study burden and improve retention rate.

\section{Statistical analyses \\ Sample size estimation}

A sample size of 160 provided $80 \%$ power to detect a minimum effect size of 0.5 standard deviations difference in the mean daily cry or fuss time between treatment groups with a significance level of $\mathrm{P}<0.05$, allowing for a dropout rate of $20 \%$ (target sample size of 128 for primary analysis). It also provided $80 \%$ power to detect a minimum effect size of 0.85 standard deviations difference in the mean daily cry or fuss time between treatment groups within either the formula fed infants or the breastfed infants, assuming $40 \%$ of infants in the sample were exclusively breast fed.

\section{Analyses}

We used Stata 12.0 to carry out analyses using the intention to treat principle. If more than $30 \%$ of data were missing in the diary at one month, we excluded the family from analysis. We considered families who lost their diaries as being lost to follow-up because they had no cry or fuss data throughout the whole study period. In unadjusted analyses, we compared all outcomes by $t$ test and non-parametric tests for continuous data, and $\chi^{2}$ tests for dichotomous data. The primary outcome was the daily duration of cry or fuss at one month. In addition, we analysed a dichotomised indicator of treatment response, defined as a $50 \%$ reduction in cry or fuss time. We planned subgroup analyses a priori to examine treatment differences separately among breastfed infants and formula fed infants, and among infants with and without a family history of atopy.

We used regression models to estimate treatment effects, as mean differences with $95 \%$ confidence intervals, adjusting for potential confounding factors identified a priori and measured at baseline. These were infant age and sex, mode of delivery, type of feeding, family history of atopy, and the respective baseline variable (for example, baseline duration of cry or fuss, number of episodes of cry or fuss, maternal depression). We repeated the regression models using bootstrapping for skewed data. For further longitudinal analyses examining trends in cry or fuss time within individual babies we used random effect regression models.

\section{Results}

\section{Participant flow and baseline characteristics}

Overall, 167 families were randomised (51\% of 329 eligible families; 85 probiotic, 82 placebo). Retention to primary outcome was $76 \%$ (127 infants analysed, 67 probiotic, 60 placebo); 11 and 29 families were excluded for loss to follow-up and missing data, respectively (fig $1 \Downarrow$ ). Other than more boys in the placebo group, the baseline characteristics of both groups were similar (table $2 \Downarrow$ ). Recruitment occurred mainly from the Royal Children's Hospital emergency department (73\%).

\section{Primary outcome}

Figure $2 \Downarrow$ plots the steady decline in daily duration of infant cry or fuss in both groups over the study period (see supplementary table 1 for values). Table $3 \Downarrow$ shows and compares all primary and secondary outcomes at 1 and 6 months.

Overall, the two groups were similar on almost all outcomes. At 1 month, the probiotic group cried or fussed an adjusted mean of 49 minutes/day more than the placebo group (95\% confidence interval 8 to $90, \mathrm{P}=0.02$ ). This was mainly due to more fussing, not more crying, in the probiotic group (adjusted mean difference 52 minutes/day, 19 to $84, \mathrm{P}=0.002$ ) at 1 month. The probiotic group fussed significantly more than the placebo group at all time points from day 7 to 1 month (see supplementary table 1). Although daily duration of cry or fuss decreased over the study period in both groups, the decline by 1 month was greater in the placebo group than probiotic group, with a mean difference in reduction of 46 minutes $(95 \%$ confidence interval -7 to $99, \mathrm{P}=0.09$ ). At 6 months, the groups did not differ for duration of cry or fuss (adjusted mean difference 7 minutes/day, $95 \%$ confidence interval -47 to 34 , $\mathrm{P}=0.75$ ).

By 1 month, 40\% (n=27) of the treatment group and $48 \%(n=29)$ of the placebo group showed at least a $50 \%$ reduction in duration of cry or fuss (odds ratio $0.7,95 \%$ confidence interval 0.4 to $1.3, \mathrm{P}=0.23)$. Results from per protocol and intention to treat analyses were similar, as were regression models performed with and without bootstrapping. No treatment effects were evident in the longitudinal analysis using random effects regression models, and no trends in treatment effect over time were evident.

\section{Secondary outcomes}

The two groups were similar on all secondary outcomes at 1 and 6 months (table 3). At 1 month, the probiotic group slept 47 minutes less a day than the placebo group (95\% confidence interval -90 to $-3, \mathrm{P}=0.04)$. Similarly, laboratory analyses of faecal samples at 1 month (treatment group $n=31$, placebo group $\mathrm{n}=34$ ) showed no differences between groups in faecal microbial diversity, calprotectin levels, or E coli load. However, infants in both groups with at least a 50\% reduction in duration of cry or fuss at 1 month had significantly lower calprotectin levels than non-responders (responders $n=50$, non-responders $n=52$, mean difference $96.6 \mathrm{mg} / \mathrm{kg}$, $95 \%$ confidence interval 5.1 to 188.1, $\mathrm{P}=0.04)$, even though microbial diversity scores and $E$ coli load were comparable.

\section{Subgroup analyses}

At 1 month, the total duration of cry or fuss was similar between treatment and placebo groups among exclusively breastfed infants (adjusted mean difference 19 minutes, 95\% confidence interval -49 to $87, \mathrm{P}=0.57, \mathrm{n}=50$ ). Durations of cry or fuss did not differ significantly between the two groups for infants aged 
more than 6 weeks, and for infants with and without a family history of atopy.

In contrast, formula fed infants in the probiotic group cried or fussed an adjusted mean of 78 minutes more (95\% confidence interval 25 to $132, \mathrm{P}=0.005, \mathrm{n}=71$ ), and infants aged 6 weeks or less in the probiotic group cried or fussed an adjusted mean of 88 minutes more ( 16 to $160, \mathrm{P}=0.02, \mathrm{n}=50$ ) than

corresponding infants in the placebo group. In both cases, this largely resulted from an increase in fussing (adjusted mean difference 63 minutes/day, 21 to $104, \mathrm{P}=0.004$ for formula fed infants, and 67 minutes/day, 8 to $126, \mathrm{P}=0.03$ for infants aged $\leq 6$ weeks).

\section{Adherence and adverse events}

Reported adherence was $82 \%$ (probiotic) and $80 \%$ (placebo), with equivalent ingested weights in both groups (mean total product ingested per baby $3.3 \mathrm{~g} v 3.9 \mathrm{~g}, \mathrm{P}=0.19$ ). Analysis of the faecal samples showed that $45 \%$ of the probiotic group and none of the placebo group were colonised with $L$ reuteri at 1 month post-intervention. No study related adverse events occurred.

\section{Discussion}

In this large community cohort of infants with colic sufficiently severe for parents to seek assistance from an emergency care setting, treatment with Lactobacillus reuteri did not reduce crying or fussing, nor was it effective in improving infant sleep, maternal mental health, family or infant functioning, or quality of life. In fact, contrary to the hypothesis, infants in the L reuteri group fussed more than those in the placebo group at all post-intervention time points except 6 months. This increased fussing occurred only in formula fed infants; $L$ reuteri did not affect crying or fussing time in exclusively breastfed infants. $L$ reuteri treatment did not lead to changes in infant faecal microbial diversity, Escherichia coli colonisation, or calprotectin levels.

\section{Strengths and limitations of this study}

This is the largest randomised controlled trial of probiotic intervention in infants with colic to date. It is the first to include formula fed infants and to extend outcomes to infant sleep, maternal mental health, and family functioning. We used rigorous methods and high quality measures; in particular, the well validated Baby Day Diary reduces carer opportunity for recall bias and is sufficiently detailed to permit separated analyses of infant crying versus fussing. Retention and reported adherence rates were high, with the final sample size adequate to achieve the predetermined statistical power and significance.

The trial has some limitations. Most of the infants were recruited from an emergency or urgent care setting; whereas our results may not therefore generalise to infants whose carers do not seek assistance, treatment in this group may be less relevant. Funding permitted completion of laboratory analyses of a subset of faecal samples collected at 1 month only. The low colonisation rate of $L$ reuteri in only $45 \%$ of the treatment infants may reflect low sensitivity of the assay used. It could also reflect low adherence, although we ascertained good adherence by parental report, and equivalent adherence between the two groups by weights of study bottles before and after ingestion of study product. It remains possible that the infants did not receive a dose of $L$ reuteri large enough to establish an effect; however, the trial's probiotic dosing was the same as that of three previous trials reported as effective. ${ }^{32-36}$ Moreover, the rate of colonisation of $L$ reuteri in normal healthy infants given the probiotic is unknown and possibly highly variable. We excluded infants with a likely diagnosis of allergy to cow's milk protein, so our results cannot generalise to this subset of infants.

\section{Interpretation in light of other studies}

Despite using the same probiotic strain, formulation, and dosing, our negative trial results contrast with the three previous trials of $L$ reuteri in infants with colic, ${ }^{32-36}$ even when considering only breastfed infants. Our trial also failed to demonstrate positive probiotic effects in formula fed infants with colic. There are several possible reasons for the differences in results. Firstly, our sample size was larger than any previous trial and was adequately blinded, unlike Savino and colleagues' trial. ${ }^{32}$ Secondly, ours was the only trial that used a validated diary to measure the primary cry or fuss outcome, reducing significantly the likelihood of recall bias and enabling us to uniquely separate out crying and fussing outcomes. Thirdly, the baseline gut microbiota of infants from Melbourne, Australia, could differ from that of Polish and Italian infants, or could be less susceptible to the effects of probiotics. Previous studies have shown that infants with allergic disease have different gut microbiota according to different geographical locations, even among countries with westernised lifestyles. ${ }^{44-48}$ Fourthly, 60\% of our infants had a family history of atopy, in keeping with local epidemiology. ${ }^{49}$ However, the prevalence of a family history of atopy was balanced between groups, and subgroup analysis of infants with and without an atopic family history was similar. Fifthly, it may be that $L$ reuteri in formula fed infants is only effective if infants are also receiving a dairy-free diet. Finally, we included infants who were receiving proton pump inhibitors at the start of the trial. However, proton pump inhibitors are ineffective in reducing crying in irritable infants $\mathrm{s}^{50} 51$ and therefore should have no impact on results.

Unexpectedly, infants in the probiotic group fussed significantly more than infants in the placebo group at all time points from day 7 to 1 month in the adjusted analyses. Further analysis revealed that carers from the placebo group had 40 to 60 minutes/day more contact (carrying/moving) with their infants at all time points, although these differences never reached significance (all $\mathrm{P}>0.05$ ). The relevance of this is uncertain, as increased contact with carers has been shown to reduce fussing and crying in infants without colic ${ }^{5253}$ but not in infants with colic. ${ }^{54}$ Previous studies have shown that in exclusively breastfed infants the use of hypoallergenic formula or dairy elimination diets in mothers is somewhat effective in reducing irritability in infants with colic. ${ }^{10-12}$ Interestingly, more infants in the placebo group were receiving hypoallergenic formula at 1 month (eight in placebo group $v$ four in probiotic group, $\mathrm{P}=0.08$ ), and more exclusively breastfed infants in the placebo group had mothers who were on dairy elimination diets at baseline (table 2 ) and at 1 month (10 in placebo group $v 3$ in probiotic group, $\mathrm{P}=0.03$ ). However, these numbers were all small, and in further analyses the results were not altered by controlling for dairy exclusion and use of hypoallergenic formulas.

In our preliminary analysis of faecal samples, calprotectin levels, although unrelated to trial arm, were lower in those with resolved colic. This finding is in keeping with a previous small study showing faecal calprotectin levels to be higher in infants with colic than in those without, ${ }^{8}$ but contrary to a larger study showing no differences in faecal calprotectin levels between infants with and without colic. ${ }^{9}$ Considering that faecal calprotectin levels are associated with intestinal neutrophilic inflammation, it is conceivable that the more than $50 \%$ reduction in crying or fussing may reflect lower levels of intestinal 
inflammation by a mechanism unrelated to probiotic ingestion. These can be further explored by better designed studies investigating faecal calprotectin levels and infant crying. When the results of our trial are added to the meta-analysis of previous randomised controlled trials of $L$ reuteri for the management of infant colic, ${ }^{31}$ the overall effectiveness of the probiotic is diminished: mean difference 48 minutes/day $(95 \%$ confidence interval -84.8 to -11.3 ) compared with 68 minutes/day ( -99.8 to -35.6 ); figures $3 \Downarrow$ and $4 \Downarrow$ ). However, it should be noted that the meta-analysis puts significant weighting on the study by Savino and colleagues, ${ }^{32}$ which was an unblinded, open label trial.

\section{Conclusions and future directions}

Based on the null findings from this large, rigorous trial, and the results from the updated meta-analysis, which has potential biases, we recommend caution in formulating recommendations regarding use of L reuteri DSM 17938 for reducing crying or fussing in breastfed, and particularly in formula fed, infants with colic. Currently, there are at least five other similar randomised controlled trials taking place in different parts of the world. ${ }^{55}$ It will be valuable to pool data from all existing and ongoing rigorous trials into an individual patient level meta-analysis to investigate with greater certainty which subgroups of infants with colic, if any, could benefit from probiotics.

Murdoch Childrens Research Institute is supported by the Victorian government's operational infrastructure support programme. The following authors were supported by Australian National Health and Medical Research Council fellowships: VS (postgraduate scholarship 607447), HH (career development award 607351), MW (career development award 546405 and senior research fellowship 1046518), and FM (capacity building grant 436914 and early career fellowship 1037449). RGB is supported by a Canada research chair in community child health research and by the Child and Family Research Institute of BC Children's Hospital. We thank all families, maternal and child health nurses, doctors, paediatricians, and research assistants (Elissa York, Jane Sheehan, Saga Arthursson, Sally Robinson) who took part in the trial, and Dawn Mount for independent coding and analysis of the diary measures. We also thank Eileen Dunne for her work in the microbiological analysis of the faecal samples.

Contributors: All authors had full access to all of the data (including statistical reports and tables) in the study and can take responsibility for the integrity of the data and the accuracy of the data analysis. VS is the guarantor, had final responsibility for the decision to submit for publication, and takes overall responsibility for all aspects of the trial and this manuscript. VS, $\mathrm{HH}$, and $\mathrm{MW}$ conceived the trial with $\mathrm{MT}, \mathrm{RH}$, and $\mathrm{FM}$. VS, $\mathrm{HH}$, and $\mathrm{MW}$ designed the intervention, with advice from $\mathrm{MT}, \mathrm{RH}$, and RGB, who also advised on measures and their interpretation. FM advised on statistical issues. AS contributed to recruitment procedures. MT advised on laboratory outcome measures and their interpretation, with input from CS and MN. MN developed and performed laboratory assays with advice and oversight from CS. All authors contributed to, read, and approved the final manuscript.

Funding: This trial was supported by the Georgina Menzies Maconachie Charitable Trust administered by Equity Trustees. BioGaia Sweden supplied the investigational product and placebo at no cost. Calpro AS supplied CalproLab ELISA kits for the analysis of calprotectin levels at no cost. BioGaia, Calpro AS, and Equitee Trustees were independent of the trial and its researchers and played no role in the trial design; in the collection, analysis, and interpretation of data; in the writing of the report; and in the decision to submit the article for publication.
Competing interests: All authors have completed the ICMJE uniform disclosure form at www.icmje.org/coi_disclosure.pdf and declare that: VS, HH, FM, and MW have support from the Australian National Health and Medical Research Council for the submitted work; RB is supported by a Canada research chair in community child health research and by the Child and Family Research Institute of BC Children's Hospital; MT is a member of the Nestlé Nutrition Institute Medical Advisory Board Oceania and the Nutricia Medical Advisory Board Australasia, received honorariums for speaking at symposiums sponsored by Nestlé Nutrition Institute and Nutricia (Danone), and received probiotic and placebo research products from Nestlé Research Centre Switzerland and Dicofarm Italy for studies unrelated to this trial; $\mathrm{RH}$ is a member of the Nestlé Nutrition Institute Medical Advisory Board Oceania and the Nutricia Medical Advisory Board Australasia and received honorariums for speaking at symposiums sponsored by Nestlé Nutrition Institute and Nutricia (Danone); the authors' spouses, partners, or children have no financial relationships that may be relevant to the submitted work; and the authors have no other relationships or activities that could appear to have influenced the submitted work.

Ethical approval: This trial was approved by the Royal Children's Hospital human research ethics committee (HREC 30111). All participants gave written informed consent before taking part.

Data sharing: The study's technical appendix is available with open access at www.rch.org.au/ccch/for_researchers/Baby_Biotics/. The statistical code is available, and anonymous patient level data may be available, from the corresponding author (valerie.sung@rch.org.au) subject to the study's material transfer agreement. Consent from participants for data sharing was not obtained but the presented data are anonymised and risk of identification is low.

Transparency: VS affirms that the manuscript is an honest, accurate, and transparent account of the study being reported; that no important aspects of the study have been omitted; and that any discrepancies from the study as planned (and, if relevant, registered) have been explained.

1 Wake M, Morton-Allen E, Poulakis Z, Hiscock H, Gallagher S, Oberklaid F. Prevalence, stability, and outcomes of cry-fuss and sleep problems in the first 2 years of life: prospective community-based study. Pediatrics 2006;117:836-42.

2 Wessel MA, Cobb JC, Jackson EB, Harris GS, Detwiler AC. Paroxysmal fussing in infancy, sometimes called "colic." Pediatrics 1954;14:421-34.

3 McMahon C, Barnett B, Kowalenko N, Tennant C, Don N. Postnatal depression, anxiety and unsettled infant behaviour. Aust N Z J Psychiatry 2001;35:581-8.

4 Howard CR, Lanphear N, Lanphear BP, Eberly S, Lawrence RA. Parental responses to infant crying and colic: the effect on breastfeeding duration. Breastfeed Med 2006:1:146-55

5 Barr RG. Preventing abusive head trauma resulting from a failure of normal interaction between infants and their caregivers. Proc Natl Acad Sci USA 2012;109(Suppl 2):17294-301.

6 Morris S, James-Roberts IS, Sleep J, Gillham P. Economic evaluation of strategies for managing crying and sleeping problems. Arch Dis Childhood 2001;84:15-9.

7 Barr RG. Excessive crying. In: Sameroff AJ, Lewis M, Miller SM, eds. Handbook of developmental psychopathology. Kluwer Academic/Plenum Press, 2000:327-50.

8 Rhoads JM, Fatheree NY, Norori J, Liu Y, Lucke JF, Tyson JE, et al. Altered fecal microflora and increased fecal calprotectin in infants with colic. $J$ Pediatr 2009;155:823-8.e1

9 Olafsdottir E, Aksnes L, Fluge G, Berstad A. Faecal calprotectin levels in infants with infantile colic, healthy infants, children with inflammatory bowel disease, children with recurrent abdominal pain and healthy children. Acta Paediatr 2002;91:45-50.

10 Cohen-Silver J, Ratnapalan S. Management of infantile colic: a review. Clin Pediatr 2009;48:14-7.

11 Garrison MM, Christakis DA. A systematic review of treatments for infant colic.[see comment]. Pediatrics 2000;106:184-90.

12 Lucassen PL, Assendelft WJ. Systematic review of treatments for infant colic. Pediatrics 2001;108:1047-8.

13 National Institute for Health and Care Excellence guidelines. Colic-infantile. Clinical knowledge summaries. 2014. http://cks.nice.org.uk/colic-infantile\#!management.

14 Heine RG. Cow's milk allergy and lactose malabsorption in infants with colic. $J$ Pediatr Gastroenterol Nutr 2013;57(Suppl 1):25-7.

15 Ghosh S, Barr RG. Colic and gas. In: Walker W, Goulet O, Kleinman R, Sherman P, Shneider B, Sanderson I, eds. Pediatric gastrointestinal disease. BC Decker, 2004:210-24.

16 Weissbluth M, Christoffel KK, Davis AT. Treatment of infantile colic with dicyclomine hydrochloride. J Pediatr 1984;104:951-5.

17 Illingworth RS. Evening colic in infants: a double-blind trial of dicyclomine hydrochloride. Lancet 1959;2:1119-20.

18 Grunseit F. Evaluation of the efficacy of dicyclomine hydrochloride ('Merbentyl') syrup in the treatment of infant colic. Curr Med Res Opin 1977;5:258-61.

19 Williams J, Watkins-Jones R. Dicyclomine: worrying symptoms associated with its use in some small babies. BMJ 1984;288:901. 


\section{What is already known on this topic}

Previous small trials suggest that the probiotic Lactobacillus reuteri effectively treats colic in breastfed infants

These studies, however, had limitations as they examined a highly selective group of infants with colic

The effects of $L$ reuteri on formula fed infants with colic are unknown

\section{What this study adds}

$L$ reuteri treatment did not reduce crying or fussing in infants with colic, nor was it effective in improving infant sleep, maternal mental health, family or infant functioning, or quality of life

Probiotics therefore cannot be routinely recommended for all infants with colic

Further research is needed to identify which subgroups of infants with colic may benefit from probiotics

20 De Weerth C, Fuentes S, Puylaert P, de Vos WM. Intestinal microbiota of infants with colic: development and specific signatures. Pediatrics 2013;131:e550-8.

21 Savino F, Cordisco L, Tarasco V, Calabrese R, Palumeri E, Matteuzzi D. Molecula identification of coliform bacteria from colicky breastfed infants. Acta Paediatr 2009;98:1582-8.

22 Savino F, Cresi F, Pautasso S, Palumeri E, Tullio V, Roana J, et al. Intestinal microflora in breastfed colicky and non-colicky infants. Acta Paediatr 2004;93:825-9.

23 Partty A, Kalliomaki M, Endo A, Salminen S, Isolauri E. Compositional development of Bifidobacterium and Lactobacillus microbiota is linked with crying and fussing in early infancy. PLoS One 2012;7.

24 Penna FJ, Peret LA, Vieira LQ, Nicoli JR. Probiotics and mucosal barrier in children. Curr Opin Clin Nutr Metab Care 2008;11:640-4.

25 Grzeskowiak L, Gronlund MM, Beckmann C, Salminen S, von Berg A, Isolauri E. The impact of perinatal probiotic intervention on gut microbiota: double-blind placebo-controlled trials in Finland and Germany. Anaerobe 2012;18:7-13.

26 Duchmann $\mathrm{R}$. The role of probiotics and antibiotics in regulating mucosal inflammation. Adv Exp Med Biol 2006;579:219-26.

27 Lutgendorff F, Akkermans LM, Soderholm JD. The role of microbiota and probiotics in stress-induced gastro-intestinal damage. Curr Mol Med 2008;8:282-98.

28 Mohan R, Koebnick C, Schildt J, Schmidt S, Mueller M, Possner M, et al. Effects of Bifidobacterium lactis Bb12 supplementation on intestinal microbiota of preterm infants: a double-blind, placebo-controlled, randomized study J Clin Microbiol 2006:44:4025-31.

29 Mentula S, Tuure T, Koskenala R, Korpela R, Kononen E. Microbial composition and fecal fermentation end products from colicky infants-a probiotic supplementation pilot. Microb Ecol Health Dis 2008;20:37-47.

30 Savino F, Cordisco L, Tarasco V, Locatelli E, Di Gioia D, Oggero R, et al. Antagonistic effect of Lactobacillus strains against gas-producing coliforms isolated from colicky infants. BMC Microbiol 2011:11:157.

31 Sung V, Collett S, De Gooyer T, Hiscock H, Tang ML, Wake M. Probiotics to prevent or treat excessive infant crying: Systematic review and meta-analysis. JAMA Pediatrics 2013;167:1150-7

32 Savino F, Pelle E, Palumeri E, Oggero R, Miniero R. Lactobacillus reuteri (American type culture collection strain 55730) versus simethicone in the treatment of infantile colic: a prospective randomized study. Pediatrics 2007;119:e124-30.

33 Savino F, Cordisco L, Tarasco V, Palumeri E, Calabrese R, Oggero R, et al. Lactobacillus reuteri DSM 17938 in infantile colic: a randomized, double-blind, placebo-controlled trial. Pediatrics 2010;126:e526-33.

34 Sung V, Hiscock H, Tang ML, Mensah FK, Heine RG, Stock A, et al. Probiotics to improve outcomes of colic in the community: protocol for the Baby Biotics randomised controlled trial. BMC Pediatr 2012;12:135.

35 Barr RG, Kramer MS, Leduc DG, Boisjoly C, McVey-White L, Pless IB. Parental diary of infant cry and fuss behavior. Arch Dis Child 1988;63:380-7.

36 Szajewska H, Gyrczuk E, Horvath A. Lactobacillus reuteri DSM 17938 for the management of infantile colic in breastfed infants: a randomized, double-blind, placebo-controlled trial. J Pediatr 2013;162:257-62.

37 Cox JL, Holden JM, Sagovski R. Detection of postnatal depression: development of a 10-item Edinburgh postnatal depression scale. Br J Psychiatry 1987:150:1172-5.

38 Varni JW, Limbers CA, Nieighbors K, Schulz K, Lieu JEC, Heffer RW, et al. The PedsQL infant scales: feasibility, internal consistency, reliability, and validity in healthy and ill infants. Qual Life Res 2010; published online 22 Aug. doi: 10.1007/s11136-010-9730-5.

39 Varni JW, Sherman SA, Burwinkle TM, Dickinson PE, Dixon P. The PedsQL ${ }^{\mathrm{TM}}$ family impact module: preliminary reliability and validity. Health Qual Life Outcomes 2004;2:55.

40 Hawthorne G, Richardson J, Atherton Day M. A comparison of the Assessment of Quality of Life (AQoL) with four other generic utility instruments. Ann Med 2001;33:358-70.
41 Osborne CA, Rees GN, Bernstein Y, Janssen PH. New threshold and confidence estimates for terminal restriction fragment length polymorphism analysis of complex bacterial communities. Appl Environ Microbiol 2006;72:1270-8.

42 Chern EC, Siefring S, Paar J, Doolittle M, Haugland RA. Comparison of quantitative PCR assays for Escherichia coli targeting ribosomal RNA and single copy genes. Lett Appl Microbiol 2011;:52:298-306.

43 CALPRO. CalproLab ELISA kit. 2012. www.calpro.no/uploads/pdf/110831_CalproLab\% 20ALP\%20ELISA.pdf.

44 Ouwehand AC, Isolauri E, He F, Hashimoto H, Benno Y, Salminen S. Differences in Bifidobacterium flora composition in allergic and healthy infants. J Allergy Clin Immunol 2001;108:144-5

45 Stsepetova J, Sepp E, Julge K, Vaughan E, Mikelsaar M, de Vos WM. Molecularly assessed shifts of Bifidobacterium ssp and less diverse microbial communities are characteristic of 5-year-old allergic children. FEMS Immunol Med Microbiol 2007;51:260-9.

46 Songjinda P, Nakayama J, Tateyama A, Tanaka S, Tsubouchi M, Kiyohara C, et al. Differences in developing intestinal microbiota between allergic and non-allergic infants: a pilot study in Japan. Biosci Biotechnol Biochem 2007;71:2338-42.

47 Suzuki S, Shimojo N, Tajiri Y, Kumemura M, Kohno Y. Differences in the composition of intestinal Bifidobacterium species and the development of allergic diseases in infants in rural Japan. Clin Exp Allergy 2007;37:506-11.

48 Gore C, Munro K, Lay C, Bibiloni R, Morris J, Woodcock A, et al. Bifidobacterium pseudocatenulatum is associated with atopic eczema: a nested case-control study investigating the fecal microbiota of infants. J Allergy Clin Immunol 2008;121:135-40.

49 Osborne NJ, Koplin JJ, Martin PE, Gurrin LC, Thiele L, Tang ML, et al. The HealthNuts population-based study of paediatric food allergy: validity, safety and acceptability. Clin Exp Allergy 2010;40:1516-22.

50 Moore DJ, Tao BS, Lines DR, Hirte C, Heddle ML, Davidson GP. Double-blind placebo-controlled trial of omeprazole in irritable infants with gastroesophageal reflux. $J$ Pediatr 2003;143:219-23.

51 Jordan B, Heine RG, Meehan M, Catto-Smith AG, Lubitz L. Effect of antireflux medication, placebo and infant mental health intervention on persistent crying: a randomized clinical trial. J Paediatr Child Health 2006;42:49-58.

52 St James-Roberts I, Alvarez M, Csipke E, Abramsky T, Goodwin J, Sorgenfrei E. Infant crying and sleeping in London, Copenhagen and when parents adopt a "proximal" form of care. Pediatrics 2006;117:e1146-55.

53 St James-Roberts I, Hurry J, Bowyer J, Barr RG. Supplementary carrying compared with advice to increase responsive parenting as interventions to prevent persistent infant crying. Pediatrics 1995;95:381-8.

54 Barr RG, McMullan SJ, Spiess H, Leduc DG, Yaremko J, Barfield R, et al. Carrying as colic "therapy": a randomized controlled trial. Pediatrics 1991;87:623-30.

55 MetaregisterOfControlledTrials. Registered trials numbers ISRCTN95287767, NCT01067027, NCT01279265, NCT01541046, NCT01017991. 2012. www.controlledtrials.com $/ \mathrm{mrct} / \mathrm{search} . \mathrm{html}$

\section{Accepted: 3 March 2014}

\section{Cite this as: BMJ 2014;348:g2107}

This is an Open Access article distributed in accordance with the Creative Commons Attribution Non Commercial (CC BY-NC 3.0) license, which permits others to distribute, remix, adapt, build upon this work non-commercially, and license their derivative works on different terms, provided the original work is properly cited and the use is non-commercial. See: http://creativecommons.org/licenses/by-nc/3.0/. 


\section{Tables}

\section{Table 1| Outcome measures (adapted from Sung et $\mathbf{a}^{34}$ )}

\begin{tabular}{|c|c|c|c|c|c|c|c|}
\hline \multirow[b]{2}{*}{ Outcomes } & \multicolumn{5}{|c|}{ Days } & \multirow{2}{*}{$\begin{array}{c}\text { Month } \\
6\end{array}$} & \multirow[b]{2}{*}{ Measure } \\
\hline & 0 & 7 & 14 & 21 & 28 & & \\
\hline \multicolumn{8}{|l|}{ Primary outcome: } \\
\hline $\begin{array}{l}\text { Daily cry/fuss time } \\
\text { (min/day) }\end{array}$ & - & - & - & - & $\mathrm{Y}$ & - & Baby's Day Diary \\
\hline \multicolumn{8}{|l|}{ Secondary outcomes: } \\
\hline $\begin{array}{l}\text { Daily cry/fuss time } \\
\text { (min/day) }\end{array}$ & Y & $\mathrm{Y}$ & $\mathrm{Y}$ & $\mathrm{Y}$ & - & Y & Baby's Day Diary \\
\hline Daily cry/fuss episodes & $\mathrm{Y}$ & $\mathrm{Y}$ & $\mathrm{Y}$ & $\mathrm{Y}$ & $\mathrm{Y}$ & Y & Baby's Day Diary \\
\hline $\begin{array}{l}\text { Infant sleep duration } \\
\text { (min/day) }\end{array}$ & $\mathrm{Y}$ & $\mathrm{Y}$ & $\mathrm{Y}$ & $\mathrm{Y}$ & $\mathrm{Y}$ & Y & Baby's Day Diary \\
\hline
\end{tabular}

(min/day)

\begin{tabular}{lllllllll}
\hline $\begin{array}{l}\text { Maternal mental health } \\
\text { scores }\end{array}$ & $Y$ & - & - & - & - & $Y$ & $Y$ & $\begin{array}{l}\text { Edinburgh postnatal } \\
\text { depression subscale }\end{array}$
\end{tabular}

Validated measure of infant crying, fussing, sleep, and feeding. Records these behaviours in 5 minute epochs over 24 hours. ${ }^{35}$ At baseline, parents record in study diary for 24 hours. At other time points, diary filled in over 48 hours (to reduce daily variability in infant behaviour while taking into account potential burden to families from filling in diary for prolonged periods)

10 item validated questionnaire to screen for depression in postpartum period, with higher scores indicating poorer mental health. ${ }^{37}$ Scores validated to detect postnatal depression in community $(\geq 10)$ and clinical $(\geq 12)$ settings

\begin{tabular}{|c|c|c|c|c|c|c|c|c|}
\hline Infant functioning scores & - & - & - & - & - & $\mathrm{Y}$ & $\begin{array}{l}\text { Paediatric quality of life } \\
\text { inventory infant subscale }\end{array}$ & $\begin{array}{l}36 \text { item validated questionnaire to measure } \\
\text { infant physical, emotional, social, and } \\
\text { cognitive functioning }^{38}\end{array}$ \\
\hline Family functioning scores & $\mathrm{Y}$ & - & - & - & $\mathrm{Y}$ & $\mathrm{Y}$ & $\begin{array}{l}\text { Paediatric quality of life } \\
\text { inventory family impact } \\
\text { subscale }\end{array}$ & $\begin{array}{l}5 \text { item validated questionnaire to assess } \\
\text { family functioning, with higher scores } \\
\text { indicating better family functioning }\end{array}$ \\
\hline $\begin{array}{l}\text { Parent quality adjusted life } \\
\text { years scores }\end{array}$ & $\mathrm{Y}$ & - & - & - & $\mathrm{Y}$ & $\mathrm{Y}$ & $\begin{array}{l}\text { Assessment of quality of } \\
\text { life (AQol-4R) }\end{array}$ & $\begin{array}{l}12 \text { item validated questionnaire to assess } \\
\text { health economic parent quality of life }{ }^{40}\end{array}$ \\
\hline $\begin{array}{l}\text { Infant faecal microbial } \\
\text { diversity }^{*}\end{array}$ & $\mathrm{Y}$ & - & - & - & $\mathrm{Y}$ & - & $\begin{array}{l}\text { 16SrDNA amplification } \\
\text { (T-RFLP) }\end{array}$ & $\begin{array}{l}\text { Terminal restriction fragment length } \\
\text { polymorphism, a molecular method to } \\
\text { investigate diversity within bacterial } \\
\text { communities, given as diversity score, with } \\
\text { higher scores indicating more microbial } \\
\text { diversity }^{41}\end{array}$ \\
\hline $\begin{array}{l}\text { Infant faecal Escherichia } \\
\text { coli colonisation }(\mathrm{cfu} / \mathrm{mL})^{*}\end{array}$ & $\mathrm{Y}$ & - & - & - & $\mathrm{Y}$ & - & $\begin{array}{l}\text { Quantitative polymerase } \\
\text { chain reaction }\end{array}$ & $\begin{array}{l}\text { Molecular method to detect and measure } \\
\text { presence of a marker gene of } E \text { coli }^{42}\end{array}$ \\
\hline $\begin{array}{l}\text { Infant faecal calprotectin } \\
(\mathrm{mg} / \mathrm{kg}) \dagger\end{array}$ & $\mathrm{Y}$ & - & - & - & $\mathrm{Y}$ & - & $\begin{array}{l}\text { Enzyme linked } \\
\text { immunosorbent assay }\end{array}$ & $\begin{array}{l}\text { To detect presence of calprotectin, a marker } \\
\text { of gut inflammation }{ }^{43}\end{array}$ \\
\hline
\end{tabular}

$\mathrm{cfu}=$ colony forming units.

*Funding allowed analysis of a subset of faecal samples collected at one month post-intervention only.

†Funding allowed analysis of first 102 faecal samples collected at one month post-intervention only. 
Table 2| Baseline characteristics. Values are numbers (percentages) unless stated otherwise

\begin{tabular}{|c|c|c|c|c|}
\hline Characteristics & No & Probiotic group & No & Placebo group \\
\hline Boys & 85 & 37 (44) & 82 & $48(59)$ \\
\hline Mean (SD) age at study entry (weeks) & & $7.5(2.9)$ & & $6.9(2.5)$ \\
\hline Mean (SD) birth weight (g) & & $3272(406)$ & & $3426(421)$ \\
\hline Mean (SD) gestation (weeks) & & $38.7(1.5)$ & & $39.1(1.4)$ \\
\hline Caesarean delivery & & $35(41)$ & & $32(39)$ \\
\hline Family history of atopy & & $51(60)$ & & $50(61)$ \\
\hline Exclusive breast feeding at entry: & & $33(39)$ & & $35(43)$ \\
\hline Dairy exclusion & 33 & $7(22)$ & 35 & $12(34)$ \\
\hline Formula use at entry: & 85 & $52(61)$ & 82 & $47(57)$ \\
\hline Hypoallergenic formula use & 52 & $7(13)$ & 47 & $8(17)$ \\
\hline Probiotic containing formula use & 52 & $18(35)$ & 47 & $15(32)$ \\
\hline Any breast feeding at entry: & 85 & $55(65)$ & 82 & $54(66)$ \\
\hline Probiotic use in any breastfeeding mother & 55 & $12(22)$ & 54 & $10(19)$ \\
\hline Supplementary probiotic use in infants at entry & 85 & $6(7)$ & 82 & $3(4)$ \\
\hline Proton pump inhibitor use in infants at entry & 80 & $21(26)$ & 68 & $24(35)$ \\
\hline Mean (SD) total daily cry/fuss time (min/day): & 75 & $328(152)$ & 65 & $329(126)$ \\
\hline Fuss time & & $153(107)$ & & $163(94)$ \\
\hline Cry time & & $175(115)$ & & $166(93)$ \\
\hline Mean (SD) daily cry/fuss episodes & & $10.3(4.9)$ & & $11.8(6.3)$ \\
\hline Mean (SD) infant sleep duration (min/day) & & $728(161)$ & & $745(141)$ \\
\hline Mean (SD) maternal mental health (EPDS score) & & $10.5(4.7)$ & & $10.6(4.6)$ \\
\hline Mean (SD) family functioning (PedsQL score) & & $71.2(23.9)$ & & $75.2(21.3)$ \\
\hline Mean (SD) parent quality adjusted life years (AQoL score) & & $0.74(0.2)$ & & $0.74(0.2)$ \\
\hline
\end{tabular}

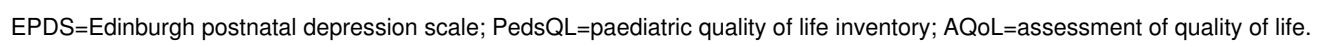




\begin{tabular}{|c|c|c|c|c|c|c|c|c|c|}
\hline \multirow[b]{2}{*}{ Outcomes } & \multicolumn{4}{|c|}{ Mean (SD) } & \multirow{2}{*}{$\begin{array}{l}\text { Adjusted mean } \\
\text { difference }{ }^{\star}(95 \% \\
\mathrm{Cl})\end{array}$} & \multirow[b]{2}{*}{$P$ value } & \multicolumn{2}{|c|}{ Median (interquartile range) } & \multirow[b]{2}{*}{$P$ value $\dagger$} \\
\hline & No & Probiotic & No & Placebo & & & Probiotic & Placebo & \\
\hline \multicolumn{10}{|l|}{1 month: } \\
\hline $\begin{array}{l}\text { Total daily cry or fuss time } \\
\text { (min/day) }\end{array}$ & 67 & $229(137)$ & 60 & $191(103)$ & 49 (8 to 90$)$ & 0.02 & $203(130-295)$ & $166(128-265)$ & 0.14 \\
\hline Fuss time (min/day) & 67 & $153(109)$ & 60 & $112(78)$ & 52 (19 to 84$)$ & 0.002 & $125(75-210)$ & $106(51-150)$ & 0.04 \\
\hline Cry time (min/day) & 67 & $76(82)$ & 60 & $79(77)$ & $-2(-28$ to 24$)$ & 0.86 & $56(13-105)$ & $63(30-100)$ & 0.4 \\
\hline Daily cry or fuss episodes & 67 & $7.5(4.7)$ & 59 & $8.1(4.9)$ & $0.4(-1.1$ to 1.8$)$ & 0.62 & $7(4-11)$ & $7(5-12)$ & 0.52 \\
\hline $\begin{array}{l}\text { Infant sleep duration } \\
\text { (min/day) }\end{array}$ & 67 & $800(141)$ & 60 & $842(119)$ & $-47(-90$ to -3$)$ & 0.04 & $818(718-903)$ & $857(772-921)$ & 0.08 \\
\hline $\begin{array}{l}\text { Maternal mental health } \\
\text { (EPDS score) }\end{array}$ & 79 & $8.2(4.7)$ & 75 & $7.9(4.9)$ & $0.6(-0.7$ to 1.9$)$ & 0.36 & $8(4-12)$ & $8(4-11)$ & 0.63 \\
\hline $\begin{array}{l}\text { Family functioning } \\
\text { (PedsQL score) }\end{array}$ & 79 & $69.8(21.6)$ & 75 & $71.1(20.8)$ & $-0.7(-6.1$ to 4.7$)$ & 0.80 & $70(56-85)$ & $75(60-85)$ & 0.70 \\
\hline $\begin{array}{l}\text { Parent quality adjusted life } \\
\text { years (AQoL score) }\end{array}$ & 79 & $0.7(0.2)$ & 74 & $0.8(0.2)$ & $0.0(-0.1$ to 0.0$)$ & 0.11 & $0.7(0.6-0.9)$ & $0.8(0.7-0.9)$ & 0.19 \\
\hline $\begin{array}{l}\text { Infant faecal microbial } \\
\text { diversity score }\end{array}$ & 28 & $32.8(1.4)$ & 27 & $30.4(1.0)$ & $-2.5 \ddagger(-5.9$ to 1.0$)$ & 0.16 & $31(28-37)$ & $31(27-35)$ & 0.34 \\
\hline $\begin{array}{l}\text { Infant faecal Escherichia } \\
\text { coli colonisation (cfu/mL) }\end{array}$ & 31 & $3.1(5.3) \times 10^{7}$ & 34 & $2.6(5.1) \times 10^{7}$ & $\begin{array}{c}-0.5 \ddagger(-3.1 \text { to } \\
\left.2.1 \times 10^{7}\right)\end{array}$ & 0.70 & $0.8(0.9-3.0) \times 10^{7}$ & $0.5(0.0-2.4) \times 10^{7}$ & 0.31 \\
\hline $\begin{array}{l}\text { Infant faecal calprotectin } \\
(\mathrm{mg} / \mathrm{kg})\end{array}$ & 53 & $230.0(36.5)$ & 49 & $197.4(28.9)$ & $\begin{array}{c}-32.6 \neq(-125.9 \text { to } \\
60.7)\end{array}$ & 0.49 & $135(74-259)$ & $114(73-242)$ & 0.63 \\
\hline \multicolumn{10}{|l|}{6 months: } \\
\hline $\begin{array}{l}\text { Total daily cry or fuss time } \\
\text { (min/day) }\end{array}$ & 65 & $122(118)$ & 58 & $131(111)$ & $-7(-47$ to 34$)$ & 0.75 & $85(55-140)$ & $105(60-160)$ & 0.27 \\
\hline Fuss time (min/day) & 65 & $84(77)$ & 58 & $84(83)$ & 0 (-29 to 29$)$ & 0.99 & $63(30-100)$ & $61(35-105)$ & 0.94 \\
\hline Cry time (min/day) & 65 & $38(56)$ & 58 & $47(52)$ & $-7(-27$ to 13$)$ & 0.49 & $18(0-45)$ & $29(10-75)$ & 0.13 \\
\hline Daily cry or fuss episodes & 65 & $5.8(5.0)$ & 58 & $6.6(4.4)$ & $-0.1(-1.8$ to 1.5$)$ & 0.87 & $4(3-8)$ & $6(3-9)$ & 0.08 \\
\hline $\begin{array}{l}\text { Infant sleep duration } \\
\text { (min/day) }\end{array}$ & 65 & $776(185)$ & 58 & $783(167)$ & 1 (-66 to 68$)$ & 0.97 & $810(720-880)$ & $807(730-870)$ & 0.98 \\
\hline $\begin{array}{l}\text { Maternal mental health } \\
\text { (EPDS score) }\end{array}$ & 69 & $6.5(4.5)$ & 63 & $7.1(4.7)$ & $-0.1(-1.6$ to 1.3$)$ & 0.84 & $6(3-9)$ & $6(3-11)$ & 0.44 \\
\hline $\begin{array}{l}\text { Family functioning } \\
\text { (PedsQL score) }\end{array}$ & 69 & $78.4(19.4)$ & 63 & $76.0(21.7)$ & $1.0(-5.5$ to 7.6$)$ & 0.76 & $80(70-95)$ & $80(60-100)$ & 0.70 \\
\hline $\begin{array}{l}\text { Infant functioning (PedsQL } \\
\text { score) }\end{array}$ & 69 & $77.7(11.4)$ & 63 & $76.3(11.1)$ & $0.9 \S(-3.1$ to 4.8$)$ & 0.66 & $78(72-84)$ & 75 (69-84) & 0.32 \\
\hline $\begin{array}{l}\text { Parent quality adjusted life } \\
\text { years (AQoL score) }\end{array}$ & 69 & $0.8(0.2)$ & 63 & $0.8(0.2)$ & $-0.1(-0.1$ to 0.0$)$ & 0.07 & $0.8(0.7-0.9)$ & $0.8(0.7-1.0)$ & 0.22 \\
\hline
\end{tabular}

cfu=colony forming units; EPDS=Edinburgh postnatal depression scale; PedsQL=paediatric quality of life inventory; AQoL=assessment of quality of life.

${ }^{*}$ Adjusted for sex, age, delivery mode, feeding type, family history of atopy, and respective baseline variable.

†Two sample Wilcoxon rank sum test.

¥Unadjusted analyses of available faecal samples.

$\S$ Adjusted for sex, age, delivery mode, feeding type, and family history of atopy. 


\section{Figures}



Fig 1 Participant flow through study
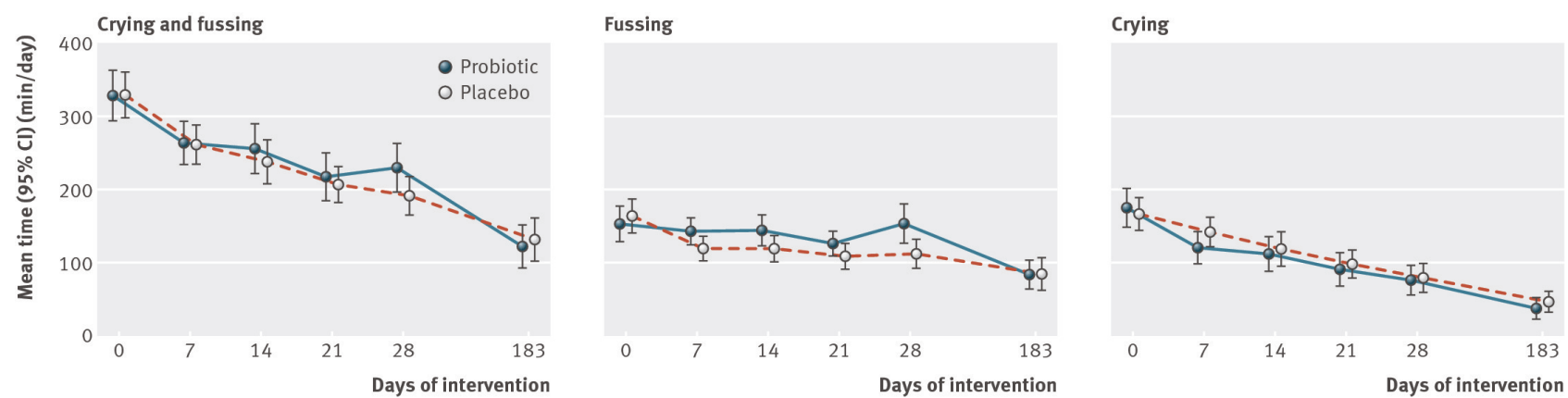

Fig 2 Daily duration of cry or fuss over study period and at 6 month follow-up. Day 28=1 month; day 183=6 months

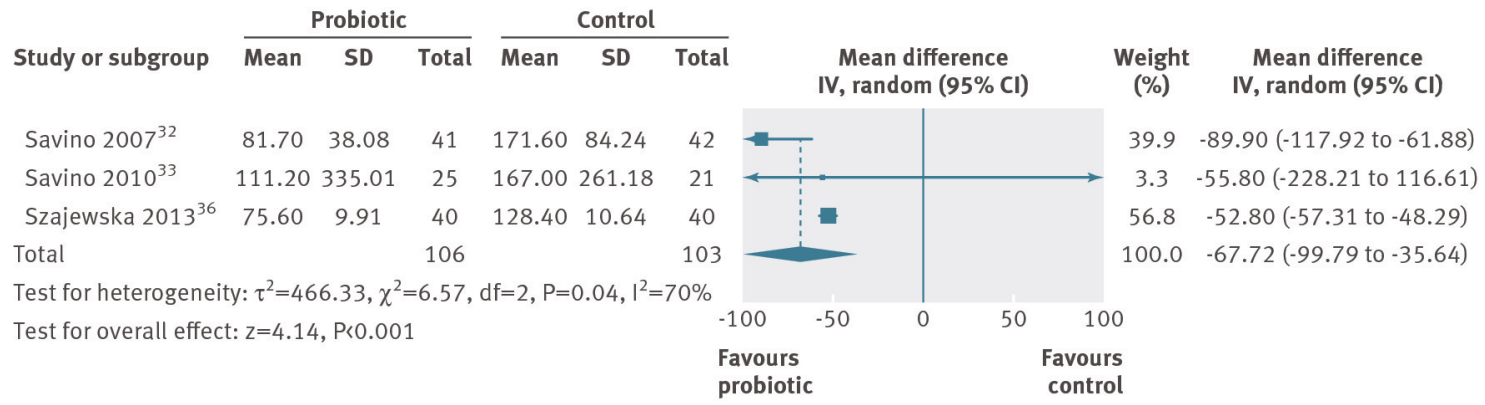

Fig 3 Meta-analysis of previous randomised controlled trials of probiotics for management of infant colic (outcomes at 21 days post-intervention) ${ }^{31}$ 


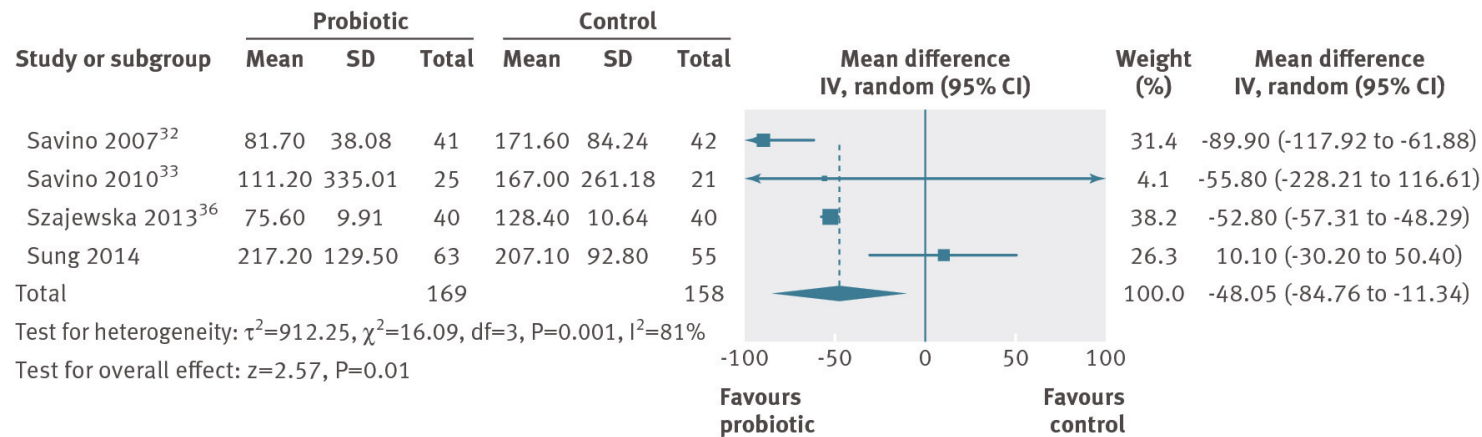

Fig 4 Meta-analysis of previous randomised controlled trials of probiotics for management of infant colic with addition of results from this study 